\title{
The effect of sampling technique on PCR-based bacteriological results of bovine milk samples
}

\author{
Heidi Hiitiö, ${ }^{* 1}$ Heli Simojoki, ${ }^{*}$ Piret Kalmus, $†$ Jani Holopainen, $\ddagger$ Satu Pyörälä, ${ }^{*}$ and Suvi Taponen* \\ ${ }^{*}$ Department of Production Animal Medicine, Faculty of Veterinary Medicine, University of Helsinki, Paroninkuja 20, 04920 Saarentaus, Mäntsälä, \\ Finland \\ †Department of Clinical Medicine, Institute of Veterinary Medicine and Animal Science, Estonian University of Life Sciences, Kreutzwaldi 62, \\ 51014, Tartu, Estonia \\ ¥Thermo Fisher Scientific Ltd., Ratastie 2, 01620 Vantaa, Finland
}

\section{ABSTRACT}

The aim of the study was to evaluate the effect of sampling technique on the microbiological results of bovine milk samples using multiplex real-time PCR. Comparison was made between a technique where the milk sample was taken directly from the udder cistern of the udder quarter using a needle and vacuum tube and conventional sampling. The effect of different cycle threshold $(\mathrm{Ct})$ cutoff limits on the results was also tested to estimate the amount of amplified DNA in the samples. A total of 113 quarters from 53 cows were tested pairwise using both techniques, and each sample was studied with real-time PCR. Sampling from the udder cistern reduced the number of species per sample compared with conventional sampling. In conventional samples, the number of positive Staphylococcus spp. results was over twice that of samples taken with the needle technique, indicating that most of the Staphylococcus spp. originated from the teat or environmental sources. The Ct values also showed that Staphylococcus spp. were present in most samples only in low numbers. Routine use of multiplex real-time PCR in mastitis diagnostics could benefit from critical evaluation of positive Staphylococcus spp. results with Ct values between 34.0 and 37.0. Our results emphasize the importance of a careful aseptic milk sampling technique and a microbiologically positive result for a milk sample should not be automatically interpreted as an intramammary infection or mastitis.

Key words: milk sampling, bovine mastitis, real-time PCR, Staphylococcus spp.

\section{INTRODUCTION}

Fast and reliable knowledge about the causative agents of bovine mastitis is crucial for mastitis manage-

Received December 23, 2015.

Accepted March 29, 2016.

${ }^{1}$ Corresponding author: heidi.hiitio@helsinki.fi ment on modern dairy farms. Certain DNA-based molecular methods, such as multiplex real-time PCR, are increasingly replacing conventional culture in mastitis diagnostics. Commercial PCR assays are available for detecting mastitis causing bacteria from quarter milk, cow composite milk, and bulk tank milk samples. Realtime PCR amplifies specific sections of bacterial DNA using predesigned oligonucleotides, and the results are given as cycle threshold $(\mathbf{C t})$ values (Koskinen et al., 2009). Cycle threshold values reflect the amount of amplified DNA, and the fewer cycles needed to reach the predefined threshold value the more DNA of the respective bacterial species is in the sample. Real-time PCR has been reported to be a sensitive and accurate diagnostic method for detecting pathogens in bovine milk samples (Koskinen et al., 2010; Spittel and Hoedemaker, 2012; Keane et al., 2013). Polymerase chain reaction technology has also been shown to provide a microbiological diagnosis for 43 to $76 \%$ of mastitic milk samples that have been tested negative when using conventional bacteriological culture (Taponen et al., 2009; Koskinen et al., 2010; Bexiga et al., 2011a).

When compared with conventional bacterial culturing, PCR diagnostics of milk samples has raised some concerns. Whereas in conventional culturing the laboratory personnel examines and interprets bacterial growth on the agar and can often identify and ignore particular colonies as likely being contaminants, in PCR diagnostics all target bacterial species detected under the set Ct cutoff value are reported. In conventional culturing, where 3 or more bacterial species are cultured from a single sample, the sample is considered to be contaminated (National Mastitis Council, 2004). Using PCR diagnostics, however, no guidelines exist on how to report multispecies results. To date, multispecies results are not excluded, yet procedures may vary across laboratories. The viability of the organisms is not known because PCR also detects DNA from dead or growth-inhibited bacteria in the milk sample. Interpretation of PCR results with low amounts of DNA, or with several species, is challenging and may not always 
fit with clinical signs of the cow. Concerns over possible false positive diagnoses, for example, leading to unnecessary use of antibiotic treatments, have emerged among veterinarians and food safety authorities in Finland.

The importance of proper aseptic milk sampling technique is well known, but milk samples taken in barn conditions are prone to contamination from environmental sources. Milk samples are drawn through the teat orifice and duct, which can be contaminated by environmental microbes residing in the site. These microbes can then appear in the milk sample. Sampling techniques that bypass the teat orifice and teat duct have been introduced for research purposes (Black et al., 1972; Honkanen-Buzalski and Bramley, 1984; Bexiga et al., 2011b). A cannula technique significantly decreased the number of samples positive for Corynebacterium spp., which are known to reside in the teat canal (Bexiga et al., 2011b).

Our hypothesis was that avoiding the teat orifice and duct completely would reduce the number of clinically irrelevant potential contaminants in the milk sample. The aim of the current study was to evaluate the effect of the sampling technique on the microbiological results of bovine milk samples using real-time PCR. For this purpose, a technique where the milk sample was taken directly from the udder cistern of the udder quarter using a needle fitted to a vacuum tube was compared with conventional sampling. The effect of different $\mathrm{Ct}$ cutoff limits on the results was also tested.

\section{MATERIALS AND METHODS}

\section{Cows}

The sampling was carried out on 2 large dairy farms in Estonia in November 2012 (herd 1: 420 cows) and June 2013 (herd 2: 700 cows). The farms belonged to the practice area of the Large Animal Clinic of the Estonian University of Life Sciences. Both barns were tiestalls with concrete floors and straw bedding. The average milk yield of herd 1 was $9,200 \mathrm{~kg}$ and that of herd 2 was $9,650 \mathrm{~kg}$.

Dairy Herd Improvement samples were taken within a month before sampling. Cows with composite milk SCC >200 000 cells/mL in the DHI results were preliminarily enrolled in the study, but extremely dirty or nervous cows were excluded to avoid excessive risk of sample contamination. California Mastitis Test (CMT) was performed for each preselected cow, and those with a CMT score $\geq 3$ on a scale of 1 to 5 in at least 1 quarter were included.

A total of 53 Holstein cows met the criteria for enrolment and were sampled: 21 cows in herd one and 32 cows in herd 2, a total of 113 quarters. All 4 quarters were sampled from 6 cows, 3 quarters from 10 cows, 2 from 22 cows, and 1 from 15 cows. Twenty-two quarters with a CMT score of 1 from 21 enrolled cows were also sampled to represent nonmastitic quarters. Average parity of the cows was 3 (median $=3$, range $=1-8$ ), and most of the cows (70\%) had calved during the winter months, from October to March. The median milk yield of the tested cows was $28.0 \mathrm{~kg} / \mathrm{d}$ (minimum = $13.0 \mathrm{~kg}$, maximum $=42.0 \mathrm{~kg}$ ) in herd 1 and $27.2 \mathrm{~kg} / \mathrm{d}$ $($ minimum $=13.5 \mathrm{~kg}$, maximum $=39.0 \mathrm{~kg})$ in herd 2 . Milk yield data are from the month when the sampling took place. We designed the sampling protocol and took all the samples. The experiment was approved by the Commission of Animal Trials at the Estonian Ministry of Agriculture (No 7.2-11/1).

\section{Milk Sampling Protocol}

Cows were sampled within $2 \mathrm{~h}$ after the morning milking. Prior to sampling, the cows were sedated with an intravenous dose of xylazine $(0.02 \mathrm{mg} / \mathrm{kg}$, Rompun $20 \mathrm{mg} / \mathrm{mL}$, Bayer Animal Health GmbH, Leverkusen, Germany). Xylazine is known to reduce milk ejection reflex (Bruckmaier and Blum, 1998), and therefore 0.5 $\mathrm{mL}$ of oxytocin (Vetox $10 \mathrm{IU} / \mathrm{mL}$, Vetcare Oy, Salo, Finland) was simultaneously administered intravenously to induce milk ejection. Visibly dirty udders were cleaned with a moist towel before sampling and foremilk was manually stripped from the quarters before CMT.

A conventional milk sample (technique A) was taken according to the routine protocol (Hogan et al., 1999): the teat end was wiped with cotton moistened in $70 \%$ ethanol until visibly clean and $10 \mathrm{~mL}$ of milk was collected in a plastic milk vial (Linkoputki $16 \times 100 \mathrm{~mm}$ Plastone, Mekalasi, Finland) without preservatives. The sampler wore disposable gloves. A second sample (technique B) was taken from the same quarter immediately after the first sample, using a needle fitted to a vacuum tube, directly from the udder cistern (Sinus lactifer, pars glandularis; Schaller, 1992). The site of puncture was chosen randomly with the easiest possible puncture line, avoiding visible veins (Figure 1). The udder skin at the puncture site was scrubbed with cotton moistened in $70 \%$ ethanol until visibly clean. Wearing a new pair of disposable plastic gloves, a 20-gauge double-ended needle (Venoject Multi-Sample, Terumo Europe N.V., Leuven, Belgium) was inserted through the udder skin into the udder cistern and milk was drawn into a 9-mL vacuum tube without preservatives (Vacuette Tube Z, Greiner Bio-One, Monroe, NC).

A total of 113 quarters were sampled using both techniques, for a total of 226 milk samples. Samples were cooled immediately and transported in cooler 
boxes to the laboratory of the Department of Production Animal Medicine (Faculty of Veterinary Medicine, University of Helsinki) within $8 \mathrm{~h}$ and thereafter stored in a refrigerator at $6^{\circ} \mathrm{C}$. The following day, milk from all samples was aseptically drawn into $2.5-\mathrm{mL}$ aliquots (Vacuette Tube Z, $4 \mathrm{~mL}$ ) and stored at $-20^{\circ} \mathrm{C}$ for PCR analysis. Remaining aliquots were stored in similar manner for later use. Milk SCC was determined with a cell counter (DCC, DeLaval Cell Counter, DeLaval Inc., Tumba, Sweden) from the samples taken using technique $\mathrm{A}$.

\section{Real-Time PCR}

Frozen samples were thawed and analyzed within a month from the sampling, using real-time PCR in the laboratory of Thermo Fisher Scientific Ltd. (Vantaa, Finland). A Thermo Scientific PathoProof Complete-16 kit was used, which contained oligonucleotides for the staphylococcal $\beta$-lactamase gene (blaZ) and for microbial species or groups of species: Corynebacterium bovis, Enterococcus faecalis and Enterococcus faecium, Escherichia coli, Klebsiella oxytoca and Klebsiella pneumoniae, Mycoplasma bovis, Mycoplasma spp., Prototheca spp., Serratia marcescens, Staphylococcus aureus, Staphylococcus spp., Streptococcus agalactiae, Streptococcus dysgalactiae, Streptococcus uberis, Trueperella pyogenes and Peptoniphilus indolicus, and yeasts. The milk sample volume for DNA extraction was $350 \mu \mathrm{L}$, which was concentrated to $100 \mu \mathrm{L}$ in the elution step of the extraction protocol. Twenty microliters of extracted

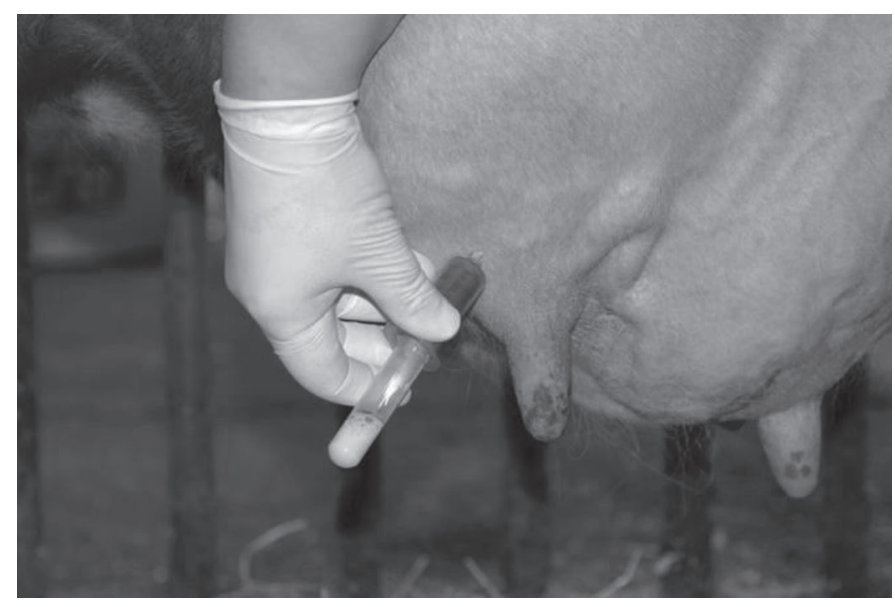

Figure 1. An experimental technique for taking a quarter milk sample (technique B). Udder skin on the sampling site was carefully disinfected before sampling. Nine milliliters of milk was drawn directly from the udder cistern with 20-gauge needle and vacuum tube with no preservatives, to avoid possible contamination from the teat orifice and canal. The site of puncture was chosen randomly with the easiest possible puncture line, avoiding visible veins.
DNA was used in PCR. Staphylococcus spp. (nonaureus staphylococci), Enterobacter spp., and Klebsiella spp. were identified to group levels. Cycle threshold values were measured up to 40.0 for each species or group and the blaZ gene reported to an accuracy of one decimal place. Cycle threshold values correlate with genome copy numbers as genomic copy number $=10^{(\mathrm{Ct}-\mathrm{x}) / \mathrm{y}}$, where $\mathrm{x}=$ slope of a standard curve and $\mathrm{y}=$ intercept of a standard curve. Consequently, the lower the $\mathrm{Ct}$ value the higher the amount of the amplified pathogen. However, the formula does not take into account possible differences in target gene or DNA fragment copy numbers within a genome. In routine use of the test, a Ct cutoff of 37.0 is used (Koskinen et al., 2009).

\section{Statistical Methods}

The effect of the sampling technique (A vs. B) on the number of different species or groups of species in the sample was compared pairwise applying Fisher's $t$-test. The comparison was carried out for $3 \mathrm{Ct}$ limits: 34.0 , 37.0, and 40.0. The limits were chosen because Ct 40.0 represents the maximum detection limit and $\mathrm{Ct} 37.0$ is the routine cutoff limit of PathoProof Mastitis Assay. A Ct limit of 34.0 should show a similar decline in the amount of amplified DNA from Ct 37.0 as the decline from Ct 40.0 to 37.0. An approximately 3.3 cycle difference in $\mathrm{Ct}$ values translates to a $\sim 10$-fold difference in the concentration of the target DNA.

The difference in the amount of detected DNA by the 2 techniques was tested separately for the most frequently detected species, C. bovis and Staphylococcus spp., using all $3 \mathrm{Ct}$ cutoff limits. Results of the paired samples were tested with Fisher`s $t$-test for paired samples using 3 different Ct cutoff limits: 34.0, 37.0, and 40.0. Agreement between the 2 sampling techniques in detecting Staphylococcus spp. or C. bovis was compared using a k-coefficient. Correlation for $\mathrm{Ct}$ values positive for Staphylococcus spp. and C. bovis using both sampling techniques were calculated with Spearman's correlation coefficient. All results with $P<0.05$ were considered statistically significant. Data were analyzed using SPSS (IBM SPSS Statistics for Windows, version 21.0.; IBM Corp., Armonk, NY).

\section{RESULTS}

\section{Cows and Milk SCC}

The total number of sampled quarters was 113 , of which $49(43.4 \%)$ were forequarters and $64(56.6 \%)$ were hindquarters. The mean SCC for all quarter milk samples was 1,748,000 cells $/ \mathrm{mL}$ (median $=901,000$ cells $/ \mathrm{mL}$, range $=32,000-5,722,000$ cells $/ \mathrm{mL}) ; 53$ 
(46.9\%) quarter samples had SCC $>1,000,000$ cells/ mL. Sixteen $(14.2 \%)$ samples originated from quarters with SCC $<100,000$ cells $/ \mathrm{mL}$, which were considered healthy (International Dairy Federation, 2013). In 4 samples milk SCC could not be determined using DCC due to clots in the milk. In these samples milk was visibly changed, and thus they were included in the study as samples with $\mathrm{SCC}>100,000$ cells $/ \mathrm{mL}$.

\section{Number of Bacterial Species per Sample}

For both sampling methods the numbers of different species or groups of species detected per sample using 3 different Ct limits (34.0, 37.0, and 40.0) are presented in Figure 2. The average number of microbial species detected per sample was significantly higher for samples taken using technique A compared with samples taken using technique $\mathrm{B}$ for all 3 Ct limits $(P$ $<0.01$ for all). One single species per sample was detected in $31(27.4 \%)$ of samples using technique A and in $55(48.7 \%)$ samples taken using technique B (Figure 2 ) using the maximum detection $\mathrm{Ct}$ limit of 40.0. The number of negative samples [i.e., in which no DNA of any target species (Ct 40.0) was detected] was 26/113 (23.0\%, technique A) and 34/113 (30.1\%, technique B). Sixteen samples taken using technique A were positive for 3 or more species using Ct 40.0, 10 samples with $\mathrm{Ct}$ 37.0, and 3 samples with Ct 34.0. Among samples taken using technique $\mathrm{B}$, the figures were 3,1 , and 0 (Figure 2) for Ct 40.0, 37.0, and 34.0, respectively.

All microbial species detected in the quarter milk samples are shown in Figure 3 (technique A) and Figure
4 (technique B). Staphylococcus spp. were most prevalent in samples taken using technique A (58.4\%), followed by $C$. bovis (46.9\%, Ct 40.0; Figure 3 ). In samples taken using technique $\mathrm{B}, C$. bovis was the most frequent species (41.6\%), followed by Staphylococcus spp. (23.9\%, Ct 40.0, Figure 4). All tested samples were negative for Serratia marcescens, Mycoplasma bovis, and Klebsiella spp. Of the 16 quarters with milk SCC $<100,000$ cells/ mL, 11 (Ct 40.0), 9 (Ct 37.0), and 3 (Ct 34.0) were positive for Staphylococcus spp. Eight samples for $C$. bovis were negative with every $\mathrm{Ct}$ limit and 3 samples for yeasts found only with $\mathrm{Ct} 40.0$ when sampled using technique A. Using technique B, 3 (Ct limit 40.0) and 2 (Ct limit 37.0) were positive for Staphylococcus spp., and 8 (Ct limits 40.0 and 37.0) and 4 (Ct limit 34.0) were positive for $C$. bovis (Figure 4 ).

\section{Results for Staphylococcus spp. and C. bovis}

The number of results positive for Staphylococcus spp. using sampling technique A was more than twice that for all $3 \mathrm{Ct}$ limits compared with results using sampling technique B (Figure 5). Lowering the $\mathrm{Ct}$ limit from 40.0 and 37.0 to 34.0 for both techniques decreased the number of positive Staphylococcus spp. detections by over $50 \%$ (Figure 5). Only 17 samples were positive for Staphylococcus spp. with both techniques, and the agreement between sampling techniques $\mathrm{A}$ and B tested with a $\kappa$-coefficient was 0.28 (Ct 40.0, $P<$ 0.01 ), indicating poor agreement between techniques. The mean Ct values for Staphylococcus spp. detections were slightly lower for samples taken using technique

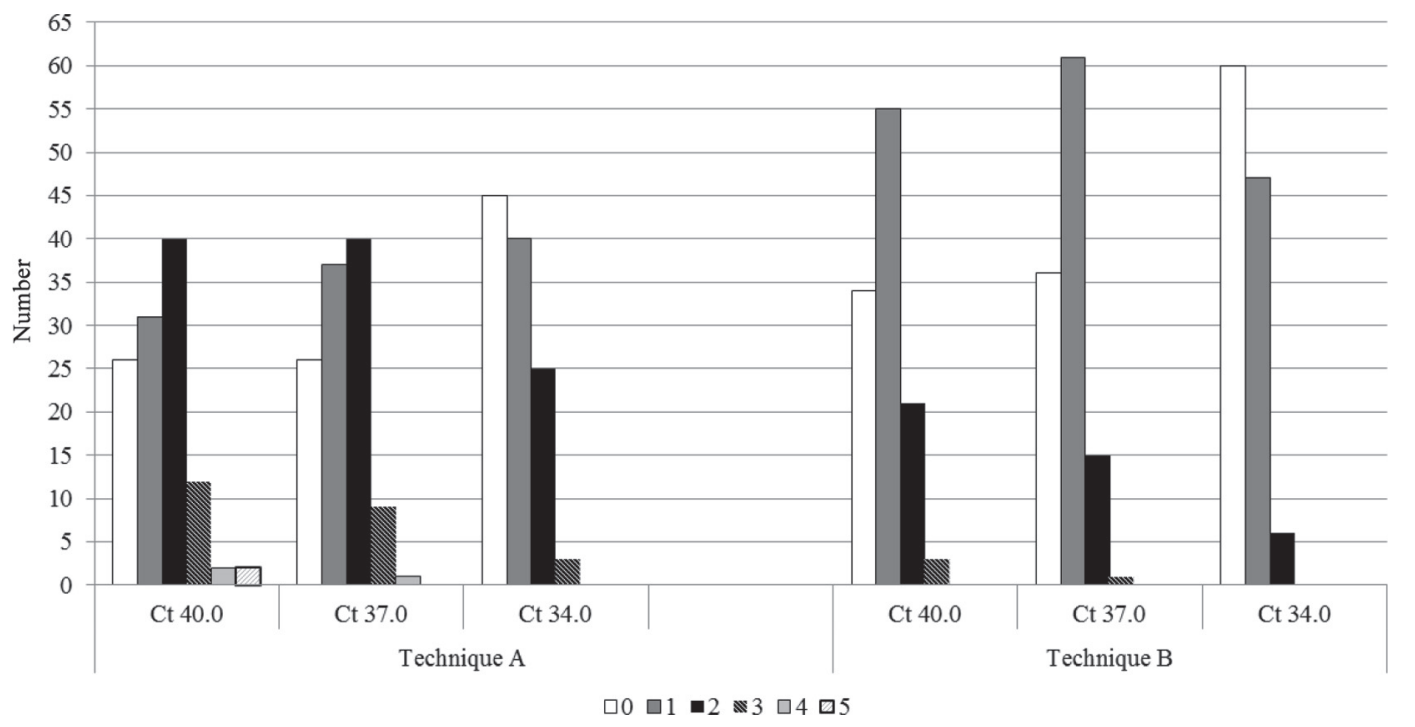

Figure 2. The number of different microbial species or groups of species per sample detected using real-time PCR in 113 quarter milk samples collected using conventional milk sampling (technique A) and in 113 experimental needle samplings (technique B). Results are presented with 3 different cycle threshold (Ct) cutoff values of 40.0, 37.0 and 34.0 (x-axis). The Ct cutoff limit of 37.0 is the current limit in routine use. 
A (mean $\mathrm{Ct}$ values $=30.5,29.7$, and 27.3) than using technique $\mathrm{B}$ (mean $\mathrm{Ct}$ values $=32.0,30.5$, and 28.5 ) with Ct cutoff limits of $40.0(P=0.01)$ and $34.0(P$ $=0.03)$. With a Ct limit of 37.0, the difference was not statistically significant $(P=0.08)$. Cycle threshold values for positive Staphylococcus spp. detections using both techniques correlated well: Spearman correlation coefficients were 0.91 (Ct 40.0, $\mathrm{n}=17$ ), 0.93 (Ct 37.0, $\mathrm{n}=14)$ and $0.86(\mathrm{Ct} 34.0, \mathrm{n}=10 ; P<0.05$ for all results).

Corynebacterium bovis was detected in 53 (Ct 40.0), 52 (Ct 37.0), and 50 (Ct 34.0) samples of the total 113 samples taken using technique A. In samples collected using technique $\mathrm{B}$, the corresponding numbers were 47,43 , and 27 (Figure 5). The number of samples that tested positive for C. bovis was 46 ( $\mathrm{Ct} \mathrm{40.0)} \mathrm{for}$ both techniques, and the agreement between sampling techniques using $\kappa$ was $0.86(P<0.01)$, which indicates excellent agreement. Mean $\mathrm{Ct}$ values for $C$. bovis detections were lower in samples taken using technique
A $(28.9,29.0$, and 28.6) than in samples using technique B (33.5, 33.1, and 31.7) for all Ct cutoff limits $(P<0.01)$. Cycle threshold values for positive $C$. bovis samples using both methods $(\mathrm{n}=46)$ did not correlate with any Ct limit tested.

\section{DISCUSSION}

Samples collected directly from the udder cistern had a lower number of different species identified per sample compared with conventional sampling via the teat canal. The result shows that a large proportion of the microbes in bovine milk samples may originate from the teat skin, teat orifice, or teat canal. Some microbes may also be of environmental origin and enter the samples during sampling. Some of the microbial DNA detected in the milk samples could thus be considered irrelevant regarding the microbiological diagnosis of IMI.

Consequently, cutoff limits of 40.0 and 37.0 yielded very similar results, but lowering the limit to 34.0

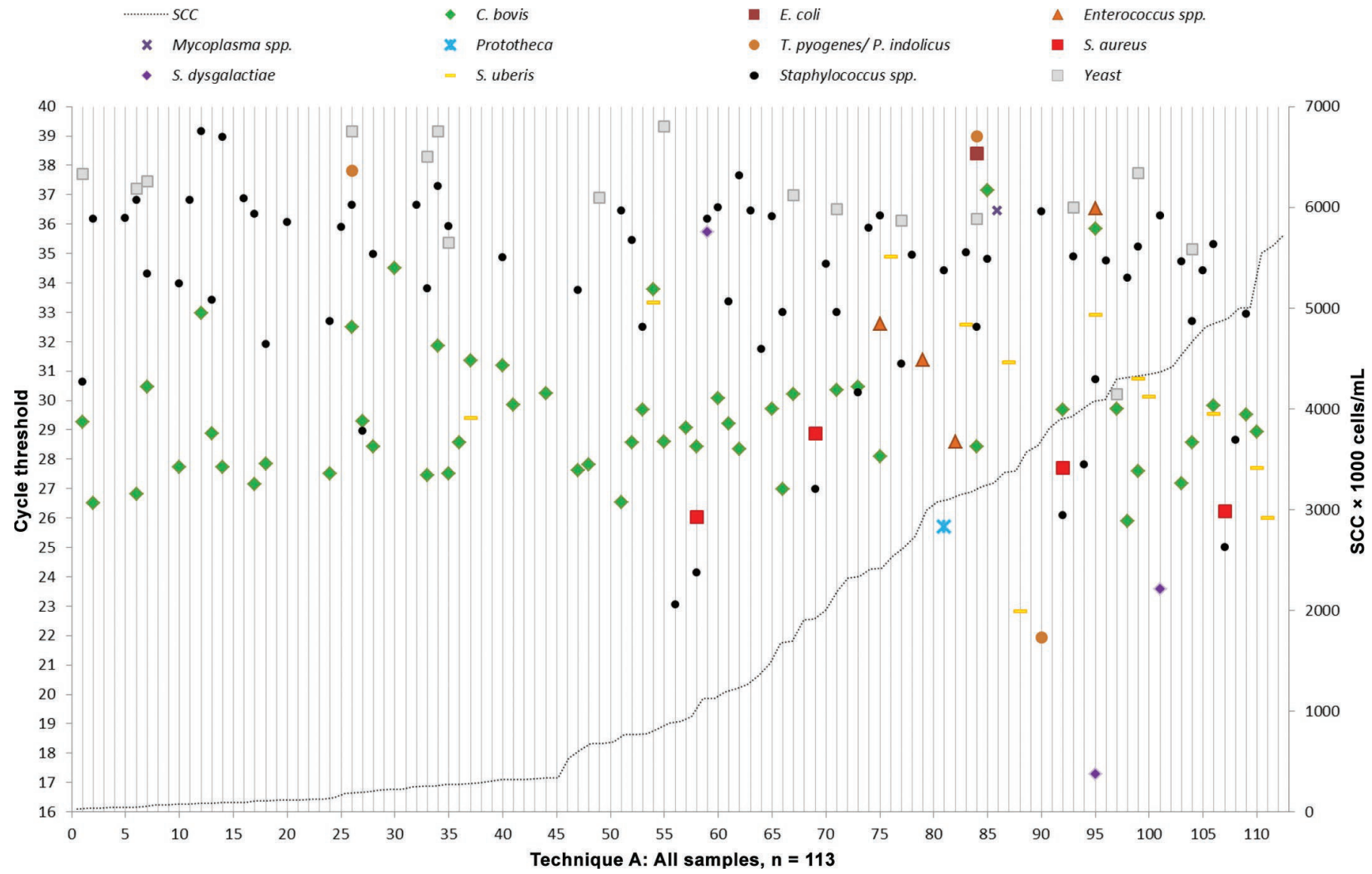

Figure 3. Bacteriological results with multiplex real-time PCR for 113 samples taken using conventional aseptic milk sampling (technique A). Each sample result is on one vertical line. Empty lines are negative samples. Samples are arranged in ascending order from left to right according to milk SCC results (range $=32,000-5,722,000$ cells $/ \mathrm{mL}$ ). S. dysgalactiae $=$ Streptococcus dysgalactiae $;$ C. bovis $=$ Corynebacterium bovis; S. uberis = Streptococcus uberis; E. coli = Escherichia coli; T. pyogenes $=$ Trueperella pyogenes; P. indolicus $=$ Peptoniphilus indolicus; S. aureus $=$ Staphylococcus aureus. 


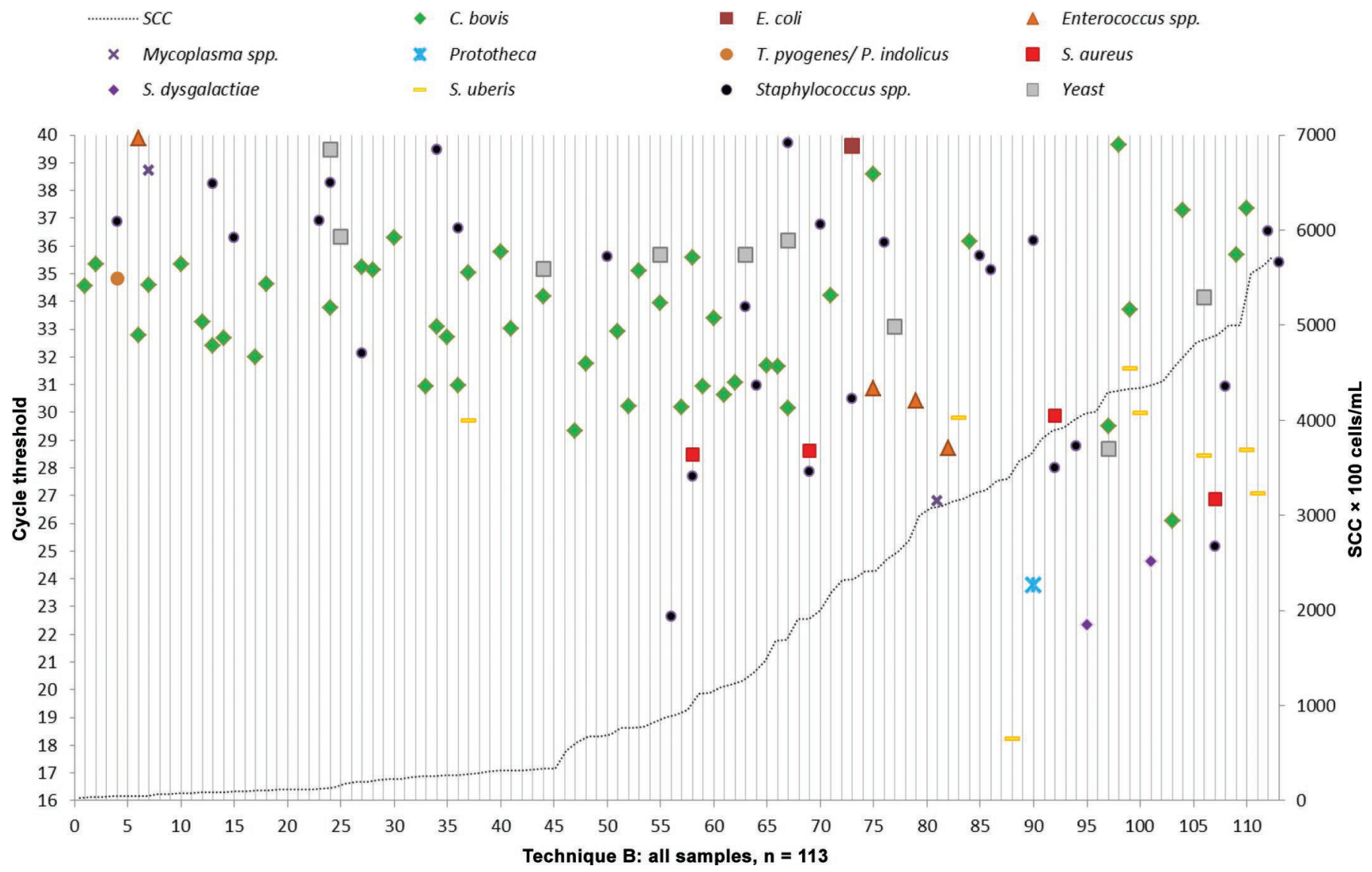

Figure 4. Bacteriological results using multiplex real-time PCR for 113 samples taken using the experimental milk sampling (technique B). Each sample result is on one vertical line. Empty lines are negative samples. Samples are arranged in ascending order from left to right according to milk SCC results (range $=32,000-5,722,000$ cells $/ \mathrm{mL}$ ). S. dysgalactiae $=$ Streptococcus dysgalactiae C. bovis $=$ Corynebacterium bovis; S. uberis $=$ Streptococcus uberis $;$ E. coli $=$ Escherichia coli; T. pyogenes $=$ Trueperella pyogenes; P. indolicus $=$ Peptoniphilus indolicus; . aureus = Staphylococcus aureus.

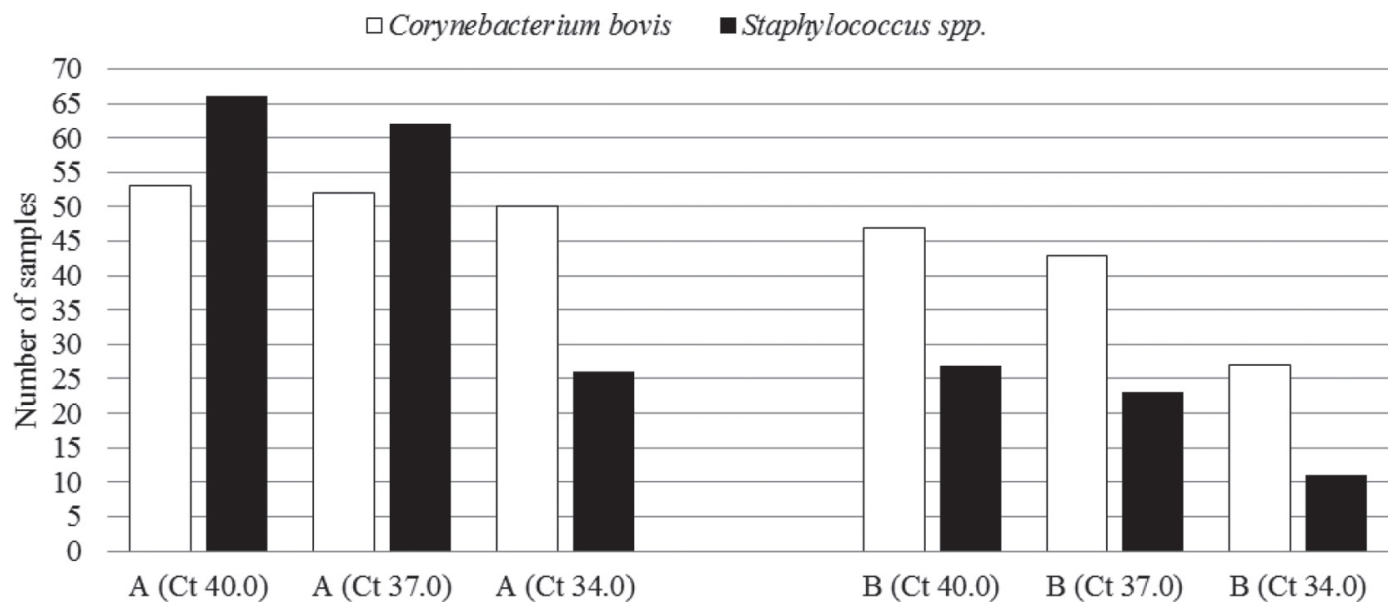

Figure 5. The number of samples positive for Corynebacterium bovis and Staphylococcus spp. (nonaureus staphylococci) taken using the conventional milk sampling technique (A) and using the experimental needle technique (B). Results are presented for 3 different cycle threshold (Ct) cutoff limits $(40.0,37.0$, and 34.0). 
significantly increased the number of negative results and number of samples containing only 1 or 2 different microbial species. The semiquantitative feature of the multiplex real-time PCR enables evaluation of the amount of amplified DNA in the sample: low Ct values indicate large amounts of amplified target DNA and vice versa. The Ct cutoff limit in routine use in Finland is 37.0 for all target species included in the test panel and all findings under this set cutoff are reported, despite the pathogenicity of the microbe.

The most significant difference between the 2 sampling techniques was for Staphylococcus spp. (nonaureus staphylococci), where the number of positive samples identified using conventional milk sampling was more than twice that for technique B (where the teat orifice and canal were completely bypassed). According to the definition of IMI being an infection of the mammary gland (International Dairy Federation, 2011), most of the positive Staphylococcus spp. findings reported here were not related to IMI because the bacteria were not present in the milk compartment. The results are in line with previous reports, as the origin of many common staphylococcal species in bovine milk samples has been suggested to be extramammary sites, including the teat apex for Staphylococcus chromogenes and Staphylococcus haemolyticus (De Vliegher et al., 2003; Vanderhaeghen et al., 2015) and teat skin or hands of the milker for Staphylococcus epidermidis (Thorberg et al., 2006; Taponen et al., 2008). Braem et al. (2013) reported a diverse microbiota on the teat apices of healthy lactating dairy cows, with CNS found on almost every teat apex sampled. Accordingly, in a study using $16 \mathrm{~S}$ rRNA gene sequence analysis, species from the Staphylococcus family were the most common group of species detected in swab samples from teat canals of dairy cows (Gill et al. 2006). Staphylococcus spp., analyzed using pyrosequencing of metagenomic $16 \mathrm{~S}$ rRNA, were also prevalent in milk samples from healthy quarters (Oikonomou et al., 2012). In our previous study, in which results from routine mastitic milk samples analyzed using realtime PCR were compared with conventional culture, more than $50 \%$ of samples positive for Staphylococcus spp. using PCR may not have been reported as IMI using bacteriological culture because of their limited ( $<5 \mathrm{cfu} / 0.01 \mathrm{~mL}$ of milk) bacterial growth on the plate (Hiitiö et al., 2015). No agreed consensus is available regarding the reporting cutoff for number of colonyforming units per $0.01 \mathrm{~mL}$ of milk for Staphylococcus spp. IMI, despite some suggestions (Dohoo et al., 2011).

Lowering of the Ct cutoff also had the greatest effect on the number of positive values for Staphylococcus spp. The amount of amplified DNA of Staphylococcus spp. was usually low, but if Staphylococcus spp. was detected in the sample using both sampling techniques, $\mathrm{Ct}$ val- ues were below 33.8 and usually under 30.0, indicating moderate or high amounts of amplified DNA.

In the present study values below the Ct cutoff 34.0 could indicate a true IMI when detected with both techniques. On the other hand, based on culture alone, evidence of cyclic shedding of bacteria exists in persisting CNS IMI (Aarestrup and Jensen, 1997; Taponen et al., 2006; Taponen et al., 2007), where the amount of CNS shed into milk varies according to stage of lactation. Based on a single bacteriological milk sample taken using the conventional technique, it is difficult to distinguish whether a positive result represents contamination or emerging, persistent or resolved IMI. Given the minor status of Staphylococcus spp. as mammary pathogens, and based on the results presented here, it might be appropriate to advise users to interpret with caution positive Staphylococcus spp. results with $\mathrm{Ct}$ values between 34.0 and 37.0. This would decrease the risk of unnecessary measures such as antibiotic treatments, which should be limited to true cases of IMI.

In samples taken using the needle technique, the most prevalent species was $C$. bovis. Surprisingly, we detected C. bovis in almost equal numbers in samples taken from the udder cistern and in conventionally taken samples. This indicates that $C$. bovis was present also in the upper regions of the udder, in contrast to findings from previous studies (Black et al., 1972; Honkanen-Buzalski and Bramley, 1984). Black et al. (1972) cultured large numbers of $C$. bovis from the teat canal, fewer from the Fürstenberg's rosette, and least from the teat cistern. Bexiga et al. (2011b) found fewer Corynebacterium spp. in bacteriological culture when the teat canal was bypassed and the sample taken via the teat with a cannula (Bexiga et al., 2011b), supporting the view that $C$. bovis is a colonizer of the teat canal. To the contrary, Gill et al. (2006) recovered C. bovis in milk samples using conventional culturing, but not in swab samples from the teat canals using molecular methods. In our study, C. bovis was detected in the upper parts of the udder, but the amount of $C$. bovis DNA amplified was higher in the conventionally taken samples than in the needle samples, which may mean that this species thrives best in the teat. Among IMI-causing organisms, C. bovis, in particular, but also Staphylococcus spp. are considered minor species. Surprisingly, in our study $C$. bovis was present both in the conventional samples and in samples from the milk compartment of the same udder quarter more often than Staphylococcus spp., indicating invasion of $C$. bovis to the upper parts of the udder (Figure 5). Lowering the Ct limit from 40.0 to 34.0 did not affect the number of samples positive for C. bovis as much as it did for Staphylococcus spp. Therefore, we found no need to adjust the cutoff for $C$. bovis. The IMI caused by $C$. bovis increases milk 
SCC compared with a healthy quarter by an average of 50,000 to 105,000 cells/mL (Honkanen-Buzalski and Bramley, 1984; Djabri et al., 2002), and the consensus on its role as a minor pathogen is well established.

Quarters with a milk SCC $<100,000$ cells/mL contained no major pathogens, irrespective of sampling technique, $C$. bovis representing the highest amounts of the amplified DNA. Only 5 (technique A) and 6 (technique B) of the healthy quarters were bacteriologically negative. Despite the careful sampling technique, contamination is always possible, particularly when using conventional sampling. According to the relatively high milk SCC in the sampled quarters, we expected to find more major pathogens. Most of the samples with a SCC $>1,000,000$ cells $/ \mathrm{mL}$ contained only Staphylococcus spp. or C. bovis. In a study carried out in Estonia, the mean SCC for quarters infected with Staphylococcus spp. was 508,000 cells/mL of milk and for quarters infected with C. bovis was 303,000 cells/mL (Haltia et al., 2006). Differences certainly exist in the pathogenicity between CNS species; some CNS species have been reported to increase quarter SCC close to that found in IMI caused by $S$. aureus (Supré et al., 2011). In a Finnish study, the milk SCC of many CNS-infected quarters increased up to millions of cells per milliliter (Taponen et al., 2007). In studies where Staphylococcus spp. was experimentally inoculated into udder quarters, milk SCC increased to millions per milliliter for a short period of time after challenge (Simojoki et al., 2009; Simojoki, 2011), but the infection dose was high.

Some pathogens not included in the PCR test panel could have possibly explained the high milk SCC without a major pathogen found in the sample. Basic bacteriological culture was done for the samples to provide preliminary results for the herd owners (data not shown), but the culture results provided no explanation for the high SCC values. It is known that milk SCC considerably increases immediately after morning milking and remains high for several hours (Olde Riekerink et al., 2007). We sampled the cows soon after morning milking, which may at least partly explain the results.

The number of samples with $\geq 3$ different species was higher in samples taken using the conventional milk sampling technique than in those using the needle technique. From the 3 multispecies B samples, containing 3 different species, in all of them 1 species was detected at notably lower amounts of DNA compared with the 2 other species (Figure 4). In these cases, udder skin could probably be the likely source of contamination, despite the careful disinfection. In conventional bacteriological culture these samples would have been defined as contaminated (Hogan et al., 1999). Our results and those from the previous study (Hiitio et al., 2015) indicate that an adequate aseptic technique for PCR testing can be achieved using the conventional sampling method, although the rate of multispecies samples is naturally higher with the more sensitive test than in studies where conventional bacteriological culture has been used (Østerås et al., 2006; Bradley et al., 2007; Koivula et al., 2007; Persson Waller et al., 2009). The procedure for contamination (i.e., to discard samples with $\geq 3$ different species) could be used for interpreting PCR results. An exception could be a sample with a maximum of 3 species where 1 is reported as the dominant species representing $>90$ or $>99 \%$ of the DNA detected. Some of the samples taken with the needle method contained blood (pinkish color), but only 1 sample was clearly red. The small amount of blood would probably not affect the results, as the samples were cooled immediately and samples were analyzed with the PCR test. The needle sampling (technique B) described here significantly reduced multispecies samples, but is invasive and not suited to routine use.

Cows included in study had elevated milk SCC at least in one quarter, and the majority of the tested quarters had SCC $>100,000$ cells $/ \mathrm{mL}$. This reflects the common situation on farms, where only cows with suspected IMI are sampled, mostly based on elevated milk SCC. Sampling more healthy quarters could have increased our knowledge on sample contamination or species residing only in teat duct or orifice, but unfortunately the number of samples in the study was limited. Our study design lacked proof of how the order of taking the conventional sample first would affect the outcome, but in the study by Bexiga et al. (2011b), where one milk sample was collected with conventional aseptic technique and the second with a cannula, no difference was seen due to the sampling order.

The bovine mammary gland is an open system and bacteria can ascend to the milk compartment from the teat. Microbes can be detected also from quarters with a low SCC, in particular using sensitive molecular methods such as real-time PCR. It must be emphasized that detecting bacteria in a milk sample does not automatically indicate an IMI. At least for clinical purposes, the microbiological results should be used only as a part of the diagnosis, together with knowledge on clinical signs and history of the cow, changes in milk appearance and elevated concentrations of indicators of inflammation, such as SCC.

\section{CONCLUSIONS}

Our results confirm the hypothesis that completely avoiding teat orifice and duct reduces the number of clinically irrelevant findings in the milk sample, as samples taken with an experimental needle technique (B) contained fewer microbial species per sample and 
more negative samples than samples taken using the conventional aseptic milk sampling technique (A). Using technique A, the number of positive Staphylococcus spp. records was over twice that for technique B. This indicates that a large proportion of Staphylococcus spp. detected in the milk samples could originate from the teat or extramammary sites. Based on our results, Staphylococcus spp. may reside only in the teat more often than $C$. bovis, which was recovered almost as often in the udder cistern samples than in the conventional samples. Cycle threshold cutoff limits of 40.0 and 37.0 yielded very similar results, but lowering the $\mathrm{Ct}$ cutoff limit to 34.0 significantly increased the number of negative samples and number of samples containing only 1 or 2 different microbial species. At the species level, lowering the Ct limit to 34.0 mostly affected the number of samples positive for Staphylococcus spp., indicating that most of the Staphylococcus spp. samples contained only low amounts of DNA. In routine use of a multiplex real-time PCR assay in mastitis diagnostics, positive Staphylococcus spp. results with $\mathrm{Ct}$ values between 34.0 and 37.0 should be interpreted with caution. Our results emphasize the importance of a proper aseptic milk sampling technique and indicate that a microbiologically positive result for a milk sample should not be automatically interpreted as an IMI or mastitis.

\section{ACKNOWLEDGMENTS}

This study was funded by Ministry of Agriculture and Forestry (Helsinki, Finland), Walter Ehrström Foundation (Helsinki, Finland), and Valio Ltd. (Helsinki, Finland).

\section{REFERENCES}

Aarestrup, F. M., and N. E. Jensen. 1997. Prevalence and duration of intramammary infection in Danish heifers during the peripartum period. J. Dairy Sci. 80:307-312.

Bexiga, R., M. T. Koskinen, J. Holopainen, C. Carneiro, H. Pereira, K. A. Ellis, and C. L. Vilela. 2011a. Diagnosis of intramammary infection in samples yielding negative results or minor pathogens in conventional bacterial culturing. J. Dairy Res. 78:49-55.

Bexiga, R., H. Pereira, O. Pereira, A. Leitão, C. Carneiro, K. A. Ellis, and C. L. Vilela. 2011b. Observed reduction in recovery of Corynebacterium spp. from bovine milk samples by use of a teat cannula. J. Dairy Res. 78:9-14.

Black, R. T., R. T. Marshall, and C. T. Bourland. 1972. Locus of mammary gland infections of Corynebacterium bovis. J. Dairy Sci. 55:413-416.

Bradley, A. J., K. A. Leach, J. E. Breen, L. E. Green, and M. J. Green. 2007. Survey of the incidence and aetiology of mastitis on dairy farms in England and Wales. Vet. Rec. 160:253-257.

Braem, G., S. De Vliegher, B. Verbist, V. Piessens, E. Van Coillie, L. De Vuyst, and F. Leroy. 2013. Unraveling the microbiota of teat apices of clinically healthy lactating dairy cows, with special emphasis on coagulase-negative staphylococci. J. Dairy Sci. 96:1499-1510.

Bruckmaier, R. M., and J. W. Blum. 1998. Oxytocin release and milk removal in ruminants. J. Dairy Sci. 81:939-949.
De Vliegher, S., H. Laevens, L. A. Devriese, G. Opsomer, J. L. M. Leroy, H. W. Barkema, and A. de Kruif. 2003. Prepartum teat apex colonization with Staphylococcus chromogenes in dairy heifers is associated with low somatic cell count in early lactation. Vet. Microbiol. 92:245-252.

Djabri, B., N. Bareille, F. Beaudeau, and H. Seegers. 2002. Quarter milk somatic cell count in infected dairy cows: A meta-analysis. Vet. Res. 33:335-357.

Dohoo, I. R., J. Smith, S. Andersen, D. F. Kelton, and S. Godden. 2011. Diagnosing intramammary infections: Evaluation of definitions based on a single milk sample. J. Dairy Sci. 94:250-261.

Gill, J. J., P. M. Sabour, J. Gong, H. Yu, K. E. Leslie, and M. W. Griffiths. 2006. Characterization of bacterial populations recovered from the teat canals of lactating dairy and beef cattle by $16 \mathrm{~S}$ rRNA gene sequence analysis. FEMS Microbiol. Ecol. 56:471-481.

Haltia, L., T. Honkanen-Buzalski, I. Spiridonova, A. Olkonen, and V. Myllys. 2006. A study of bovine mastitis, milking procedures and management practices on 25 Estonian dairy herds. Acta Vet. Scand. 48:22.

Hiitiö, H., R. Riva, T. Autio, T. Pohjanvirta, J. Holopainen, S. Pyörälä, and S. Pelkonen. 2015. Performance of a real-time PCR assay in routine bovine mastitis diagnostics compared with indepth conventional culture. J. Dairy Res. 82:200-208.

Hogan, J., R. González, R. Harmon, S. Nickerson, S. Oliver, J. Pankey, and K. Smith. 1999. Laboratory handbook on bovine mastitis. National Mastitis Council, Madison, WI.

Honkanen-Buzalski, T., and A. J. Bramley. 1984. Observations on $\mathrm{Co}^{-}$ rynebacterium bovis infection of the bovine mammary gland. II. experimental infection. J. Dairy Res. 51:379-385.

International Dairy Federation. 2011. Suggested interpretation of mastitis terminology. Bulletin of the International Dairy Federation. 448/2011. IDF, Brussels, Belgium.

International Dairy Federation. 2013. Guidelines for the use and interpretation of bovine milk somatic cell counts (SCC) in the dairy industry. Bulletin of the International Dairy Federation. 466/2013. IDF, Brussels, Belgium.

Keane, O. M., K. E. Budd, J. Flynn, and F. McCoy. 2013. Increased detection of mastitis pathogens by real-time PCR compared to bacterial culture. Vet. Rec. 173:268-273.

Koivula, M., A. Pitkälä, S. Pyörälä, and E. Mäntysaari. 2007. Distribution of bacteria and seasonal and regional effects in a new database for mastitis pathogens in Finland. Acta Agric. Scand. A Anim. 57:89-96.

Koskinen, M. T., J. Holopainen, S. Pyörälä, P. Bredbacka, A. Pitkälä, H. W. Barkema, R. Bexiga, J. Roberson, L. Sølverød, R. Piccinini, D. Kelton, H. Lehmusto, S. Niskala, and L. Salmikivi. 2009. Analytical specificity and sensitivity of a real-time polymerase chain reaction assay for identification of bovine mastitis pathogens. J. Dairy Sci. 92:952.

Koskinen, M. T., G. J. Wellenberg, O. C. Sampimon, J. Holopainen, A. Rothkamp, L. Salmikivi, W. A. van Haeringen, T. J. G. M. Lam, and S. Pyörälä. 2010. Field comparison of real-time polymerase chain reaction and bacterial culture for identification of bovine mastitis bacteria. J. Dairy Sci. 93:5707.

National Mastitis Council. 2004. Microbiological Procedures for the Diagnosis of Bovine Udder Infection and Determination of Milk Quality. 4th ed. NMC, Madison, WI.

Oikonomou, G., V. S. Machado, C. Santisteban, Y. H. Schukken, and R. C. Bicalho. 2012. Microbial diversity of bovine mastitic milk as described by pyrosequencing of metagenomic 16s rDNA. PLoS ONE 7:1-14.

Olde Riekerink, R. G. M., H. W. Barkema, W. Veenstra, F. E. Berg, H. Stryhn, and R. N. Zadoks. 2007. Somatic cell count during and between milkings. J. Dairy Sci. 90:3733-3741.

Østerås, O., L. Sølverød, and O. Reksen. 2006. Milk culture results in a large Norwegian survey -Effects of season, parity, days in milk, resistance, and clustering. J. Dairy Sci. 89:1010-1023.

Persson Waller, K., B. Bengtsson, A. Lindberg, A. Nyman, and H Ericsson Unnerstad. 2009. Incidence of mastitis and bacterial findings at clinical mastitis in Swedish primiparous cows-Influence of breed and stage of lactation. Vet. Microbiol. 134:89-94. 
Schaller, O., ed. 1992. Illustrated Veterinary Anatomical Nomenclature. Ferdinand Enke Verlag, Stuttgart, Germany.

Simojoki, H. 2011. Innate immune response in experimentally induced bovine intramammary infection with Staphylococcus simulans and S. epidermidis. Vet. Res. 42:49.

Simojoki, H., T. Orro, S. Taponen, and S. Pyörälä. 2009. Host response in bovine mastitis experimentally induced with Staphylococcus chromogenes. Vet. Microbiol. 134:95-99.

Spittel, S., and M. Hoedemaker. 2012. Mastitis diagnosis in dairy cows using PathoProof real-time polymerase chain reaction assay in comparison with conventional bacterial culture in a northern German field study. Berl. Munch. Tierarztl. Wochenschr. 125:494-502.

Supré, K., F. Haesebrouck, R. Zadoks, M. Vaneechoutte, S. Piepers, and S. DeVliegher. 2011. Some coagulase-negative staphylococcus species affect udder health more than others. J. Dairy Sci. 94:2329-2340.

Taponen, S., J. Björkroth, and S. Pyörälä. 2008. Coagulase-negative staphylococci isolated from bovine extramammary sites and intramammary infections in a single dairy herd. J. Dairy Res. 75:422429

Taponen, S., J. Koort, J. Björkroth, H. Saloniemi, and S. Pyörälä. 2007. Bovine intramammary infections caused by coagulase-nega- tive staphylococci may persist throughout lactation according to amplified fragment length polymorphism-based analysis. J. Dairy Sci. 90:3301-3307.

Taponen, S., L. Salmikivi, H. Simojoki, M. T. Koskinen, and S. Pyörälä. 2009. Real-time polymerase chain reaction-based identification of bacteria in milk samples from bovine clinical mastitis with no growth in conventional culturing. J. Dairy Sci. 92:26102617.

Taponen, S., H. Simojoki, M. Haveri, H. D. Larsen, and S. Pyörälä. 2006. Clinical characteristics and persistence of bovine mastitis caused by different species of coagulase-negative staphylococci identified with API or AFLP. Vet. Microbiol. 115:199-207.

Thorberg, B.-M., I. Kühn, F. M. Aarestrup, B. Brändström, P. Jonsson, and M. Danielsson-Tham. 2006. Pheno- and genotyping of Staphylococcus epidermidis isolated from bovine milk and human skin. Vet. Microbiol. 115:163-172.

Vanderhaeghen, W., S. Piepers, F. Leroy, E. Van Coillie, F. Haesebrouck, and S. De Vliegher. 2015. Identification, typing, ecology and epidemiology of coagulase negative staphylococci associated with ruminants. Vet. J. 203:44-51. 